\title{
The analysis of surface topography during turning of Waspaloy with the application of response surface method
}

\author{
Damian Przestacki ${ }^{1, a}$, Tadeusz Chwalczuk $^{1}$ \\ ${ }^{1}$ Poznan University of Technology, Institute of Mechanical Technology, Piotrowo 3, Poznan 60-965, Poland
}

\begin{abstract}
This paper presents the analysis of surface topography during longitudinal turning of Waspaloy. The primary objective of the work was to determine the optimal machining conditions enabling the minimization of surface roughness parameters. Experimental studies were performed with the application of fractional plan (with 1 block and 9 systems). The carried out experiment included the measurements of surface topographies formed after turning with variable cutting conditions (cutting speed $v_{c}$, cutting depth $a_{p}$ and feed $f$ ). Subsequently the measured quantities have been applied to the optimization procedure based on the application of response surface method (RSM). In order to obtain the optimal cutting parameters, the maximization of total utility function was carried out. Results revealed that the minimal surface roughness parameters values during turning of Waspaloy with the cubic boron nitride $(\mathrm{CBN})$ inserts can be obtained for the: $f=0.05 \mathrm{~mm} / \mathrm{rev}, a_{p}=0.23 \mathrm{~mm}$ and $v_{c}=452 \mathrm{~m} / \mathrm{min}$.
\end{abstract}

\section{Introduction}

Advanced aerospace nickel-based alloys are designed to work in very heavy loads at the elevated temperatures. Nevertheless, these super alloys have low machinability because of their properties focused on improved resistance to hot corrosion, oxidation, creep strain and dwell crack growth, higher stability of the microstructure and yield stress at the high temperature [1]. According to Ezugwu et al. [2], the nickel-based superalloys can be characterized by the three distinct groups, namely: nickel-copper, nickel-chromium and nickel-molybdenum-chromium.

Waspaloy is a nickel-chromium alloy with very high strength at the elevated temperatures and excellent corrosion resistance. Primarily, this material is applied in aerospace and automotive industries due to its high corrosion resistance and strength at high temperatures. Nevertheless, these unique exploitation properties significantly hinder Waspaloy's machinability. The primary problems occurring during machining of Waspaloy are intense tool wear [3, 4] and high surface roughness [5]. According to Takur and Gangopadhyay [6], during machining of nickel-based alloys, surface roughness is strongly affected by the three major factors: the initiation of workpiece material's plastic side flow, the appearance of built up edge, and the progression of tool wear. In addition, the machined surface profile can contain also the defects including feed marks, laps and grooves [7]. In order to improve the machinability of hard-to-cut materials, the modern machining trends can be applied. These methods include the high speed machining (HSM) [8-10], the laser assisted machining (LAM) [11-13], as well as the machining with the application of minimum quantity cooling lubrication

\footnotetext{
${ }^{\mathrm{a}}$ Corresponding author : damian.przestacki@put.poznan.pl
} 
(MQCL) $[14,15]$. Another method which can be successfully applied to select the effective machining conditions, enabling the improvement of process efficiency or quality, is the optimization. The machining process' optimization objectives are usually focused on the minimization of surface roughness [16], cutting forces [17], elongation of tool life [18], reduction of tool wear [19] and machining vibrations [20]. The popular optimization approaches are mainly based on the Taguchi method and determination of signal-to-noise ratio, grey relational analysis (GRA), as well as the response surface methodology (RSM). Nevertheless, the researches focused on the optimization of Waspaloy machining process have not been reported in literature.

The literature survey reveals that despite many researches regarding the nickel-based superalloys, the machinability of Waspaloy is insufficiently recognized. Therefore, this study is focused on the evaluation of surface topography and roughness parameters during turning of Waspaloy material. The carried out research involves the optimization of cutting parameters (feed per revolution $f$, cutting depth, $a_{p}$ and cutting speed $v_{c}$ ), allowing the improvement of surface finish obtained after longitudinal turning of Waspaloy.

\section{Experimental details}

\subsection{Work and tool materials}

The Waspaloy super alloy was used as the workpiece material. Its chemical composition is depicted in Table 1 [5]. The workpieces were provided as a cylinders with a diameter of $80 \mathrm{~mm}$. The longitudinal turning tests were conducted with the application of the cubic boron nitride CBN7015 inserts with the VBGW 160408 S01020F symbol and the following geometry: tool major cutting edge angle $\kappa_{r}=72.5^{\circ}$, flank angle in the feed motion direction $\alpha_{f}=5^{\circ}$, and tool radius $r_{\varepsilon}=0.8 \mathrm{~mm}$.

TABLE 1. Chemical composition of waspaloy [\%]

\begin{tabular}{cc}
\hline \hline Element & Content \\
\hline $\mathrm{C}$ & 0.036 \\
$\mathrm{~S}$ & 0.0004 \\
$\mathrm{Mn}$ & 0.03 \\
$\mathrm{Si}$ & 0.05 \\
$\mathrm{Cr}$ & 19.87 \\
$\mathrm{Mo}$ & 4.27 \\
$\mathrm{Co}$ & 13.26 \\
$\mathrm{Ti}$ & 3.08 \\
$\mathrm{Al}$ & 1.35 \\
$\mathrm{~B}$ & 0.007 \\
$\mathrm{Zr}$ & 0.06 \\
$\mathrm{Fe}$ & 0.09 \\
$\mathrm{Cu}$ & 0.01 \\
$\mathrm{Ni}$ & 57.32 \\
$\mathrm{P}$ & 0.004 \\
\hline \hline
\end{tabular}

\subsection{Machining tests}

The experiments (see - Tab. 2) involved the longitudinal turning without fluids, carried out on precise TUR 560E lathe with variable cutting speed $v_{c}$, cutting depth $a_{p}$ and feed $f$. The experiment was designed with the application of fractional plan (with 1 block and 9 systems) in order to reduce the time and costs of carried out tests. 
Table 2. Design of experiment

\begin{tabular}{|c|c|c|c|c|c|c|}
\hline No & \multicolumn{3}{|c|}{ Level of variability } & $\begin{array}{c}\text { Feed } \\
f[\mathrm{~mm} / \mathrm{rev}]\end{array}$ & $\begin{array}{c}\text { Cutting speed } \\
v_{c}[\mathrm{~m} / \mathrm{min}]\end{array}$ & $\begin{array}{c}\text { Depth of cut } \\
a_{p}[\mathrm{~mm}]\end{array}$ \\
\hline 1 & 0 & 1 & -1 & 0.040 & 226 & 0.30 \\
\hline 2 & -1 & -1 & -1 & 0.040 & 89 & 0.10 \\
\hline 3 & -1 & 0 & 1 & 0.112 & 89 & 0.20 \\
\hline 4 & 1 & 1 & 1 & 0.112 & 452 & 0.30 \\
\hline 5 & 1 & -1 & 0 & 0.077 & 452 & 0.10 \\
\hline 6 & -1 & 1 & 0 & 0.077 & 89 & 0.30 \\
\hline 7 & 1 & 0 & -1 & 0.040 & 452 & 0.20 \\
\hline 8 & 0 & 0 & 0 & 0.077 & 226 & 0.20 \\
\hline 9 & 0 & -1 & -1 & 0.112 & 226 & 0.10 \\
\hline
\end{tabular}

\subsection{Inspection of topography}

The surface profile meter, type Veeco NT 1100 has been applied to the evaluation of surface topography. The measurements were made with 5.1-fold magnification. The measurements were repeated 3 times for the each investigated machined surface. The acquired signals were processed in Veeco Vision 32 software. As a consequence, the average surface roughness $R a$ and surface roughness height $R z$ were determined.

\subsection{Optimization of Waspaloy turning process}

The multi-criteria optimization procedure was applied in the research. This optimization was based on the transformation of the approximated output factors' values into the singular value of the resultant total utility $U_{\text {tot }}$. Thus, the problem of simultaneous optimization of many output factors was simplified to the determination of one output parameter, which maximizes total response utility. In the carried out research, the $R a$ and $R z$ surface roughness parameters were applied as an optimization criteria. In the first part, the turning tests conducted on the basis of the fractional experimental design were carried out. The obtained tests' results were the starting point to the definition of response utility profile, formulated for the investigated output factors $(R a, R z)$. During this optimization stage, all output factors' values were assigned to the partial utilities, which values were contained in the range: $<0,1>$. After the definition of response utility profiles, the optimal solution's searching procedure was applied. This procedure included the mesh definition of the input variables. Subsequently, the output factors' predictive values were calculated for the all mesh points and as a result, the partial utility values were received. In order to determine the total utility value, the mean geometric values of partial utilities were calculated in the each mesh point. The next step involved the formulation of the total utility model, with the application of spline function. After the generation of this model, the optimal solution searching algorithm was adopted. The optimal solution determines the values of input variables, corresponding to maximal value of the total utility. In order to achieve it, the simplex method implemented in the StatSoft Statistica 13.1 software was applied. Ultimately, the optimal input parameters' values were received.

\section{Results and discussion}

The surface topographies, obtained during turning in the range of the lowest (experiment 2) and the highest (experiment 4) levels of selected cutting parameters are presented in figure 1. It can be observed that for the both investigated cases (Fig. 1a, Fig. 1b), the feed marks on surface topographies are seen, resulting from the kinematic-geometric model [21]. Furthermore, in case of the lowest 
selected cutting parameters, the surface topography is less regular and characterized by the appearance of burrs located mainly at the peaks of irregularities. This phenomenon can be attributed to the high ploughing action, resulting from the intense elastic-plastic deformations of workpiece occurring at the low chip thicknesses (correlated with feed and depth of cut values).

a)

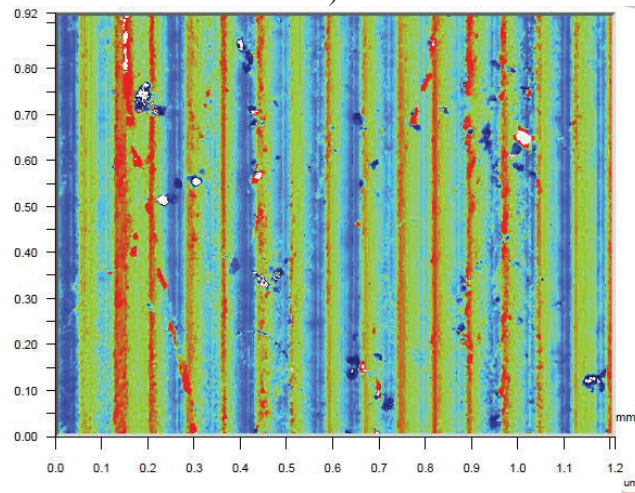

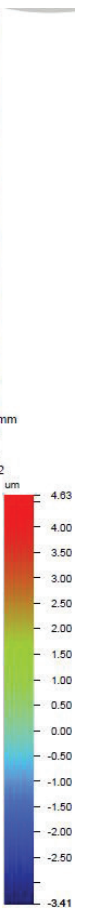

b)
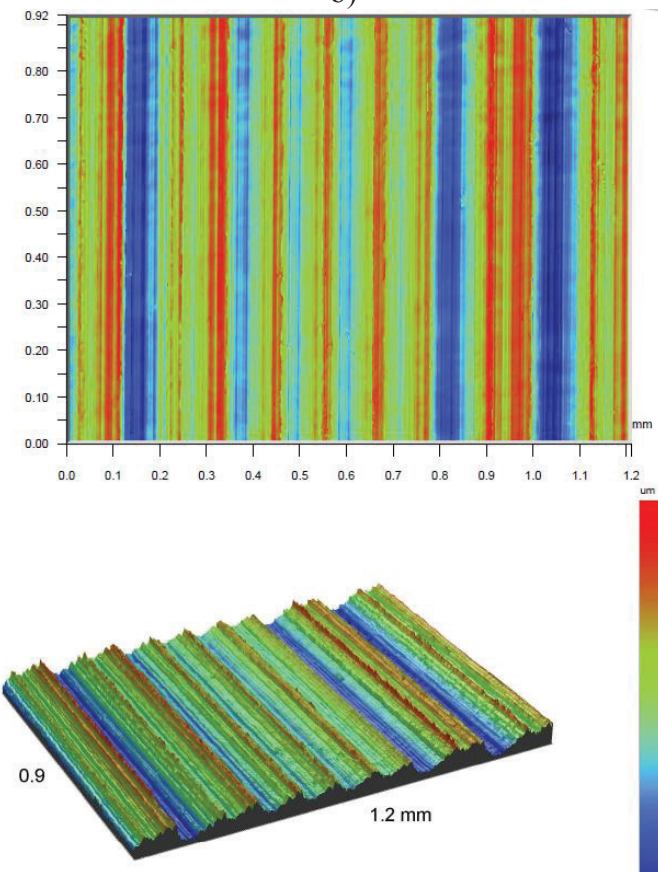

Figure 1. Surface topographies of Waspaloy samples obtained during turning with: a) $v_{c}=89 \mathrm{~m} / \mathrm{min}$, $a_{p}=0.1 \mathrm{~mm} ; f=0.04 \mathrm{~mm} /$ tooth; b) $v_{c}=452 \mathrm{~m} / \mathrm{min}, a_{p}=0.3 \mathrm{~mm} ; f=0.112 \mathrm{~mm} /$ tooth.

The analysis of surface roughness $R a$ response surfaces, formulated for the investigated cutting parameters (Fig. 2), shows similar qualitative relations independently on selected cutting depth. From these figures it can be seen, that surface roughness $R a$ values have an increasing trend with the growth of feed per revolution. This is a typical relation resulting from the traditional kinematic-geometric surface roughness model. In case of cutting speed, the highest surface roughness values were obtained for the moderate $v_{c}$ values, independently on selected feed per revolution. Figures $2 \mathrm{a}-2 \mathrm{c}$ show also that during turning with the lowest selected cutting depth values, the surface roughness $R a$ parameters are the highest. This relation can be explained by the occurrence of burrs, located at the irregularity peaks (see - Fig. 1a), which can be caused by the ploughing phenomena occurring at the low chip thicknesses.

The resultant total utility function for the cutting speed $v_{c}$, depth of cut $a_{p}$, and feed per revolution $f$ is presented in Figure 3. The maximal value of total utility function $U_{t o t}$ is achieved with feed per revolution $f=0.05 \mathrm{~mm} / \mathrm{rev}$, cutting depth $a_{p}=0.23 \mathrm{~mm}$ and cutting speed $v_{c}=452 \mathrm{~m} / \mathrm{min}$. The application of these optimal cutting parameters gave surface roughness parameters $R a<0.5 \mu \mathrm{m}$ and $R z<3.5 \mu \mathrm{m}$.

It can be also concluded (Figure 3) that the optimum cutting parameters are for the highest value of cutting speed. The selection of the higher cutting speeds during machining of Waspaloy can result in the growth of tool wear intensity. Therefore, the further studies, focused on the analysis of tool wear in function of cutting speed are required to verify the validity of the carried out optimization. 
a)

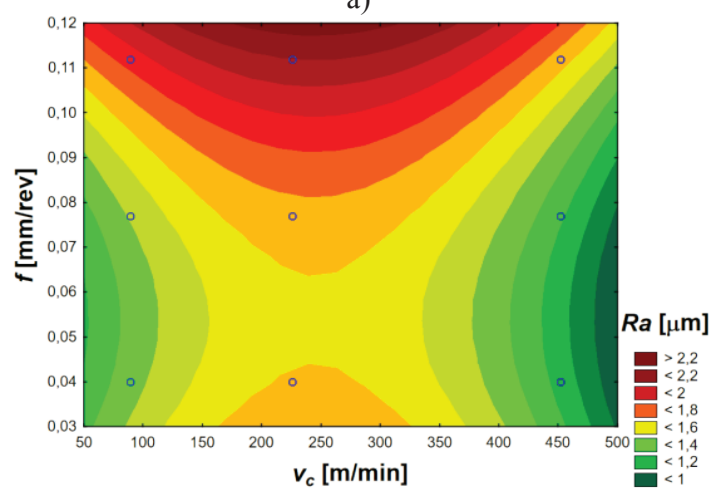

b)

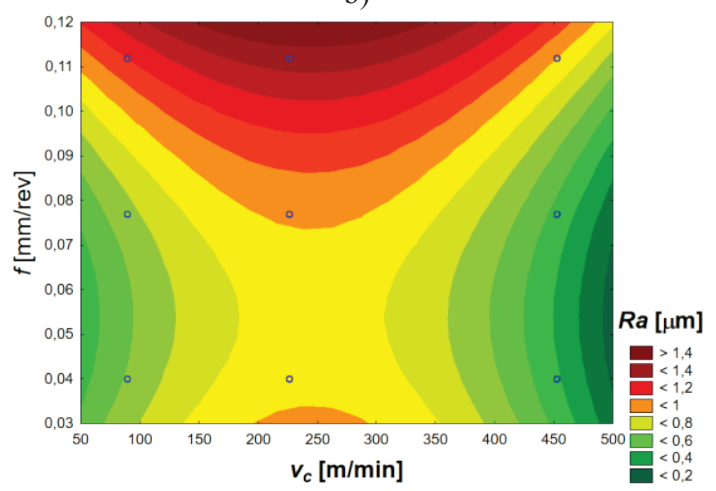

c)

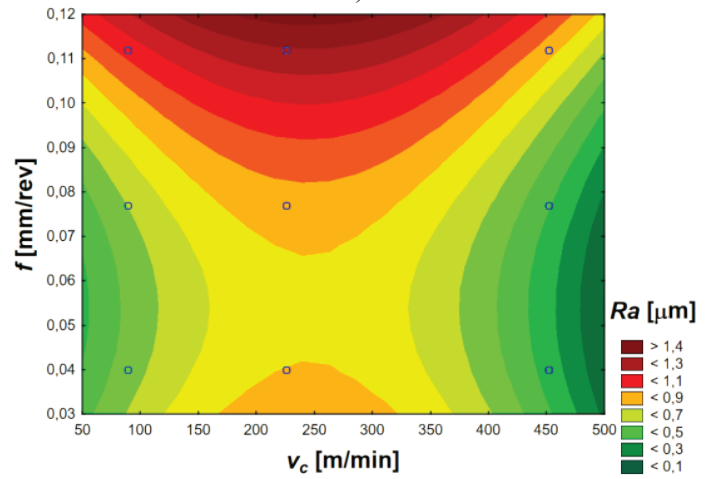

Figure 2. Surface roughness $R a$ parameters of Waspaloy samples obtained during turning with: a) $a_{p}=0.1 \mathrm{~mm}$; b) $a_{p}=0.2 \mathrm{~mm}$; c) $a_{p}=0.3 \mathrm{~mm}$.
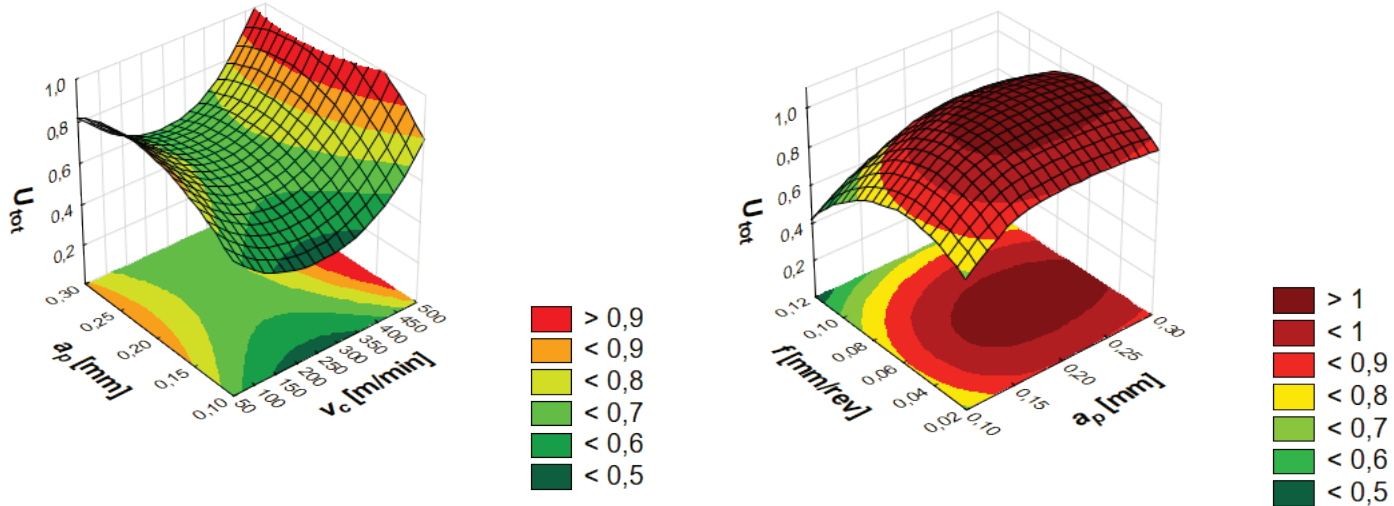

Figure 3. Total utility function for the cutting speed $v_{c}$, depth of cut $a_{p}$, and feed per revolution $f$.

\section{Conclusions}

On the basis of conducted research, focused on the analysis of surface topography during longitudinal turning of Waspaloy, the following conclusions have been formulated:

- the feed marks on surface topographies are seen, independently on the selected cutting parameters. In addition, in case of the lowest tested cutting parameters, the surface topography is less regular and characterized by the appearance of burrs located mainly at the peaks of irregularities;

- during turning with the lowest investigated cutting depth values, the surface roughness $R a$ values are the highest. This relation can be attributed to ploughing phenomena occurring at the low chip 
thicknesses;

- based on the conducted optimization, the following optimal turning parameters were obtained: $f=$ $0.05 \mathrm{~mm} / \mathrm{rev}, a_{p}=0.23 \mathrm{~mm}, v_{c}=452 \mathrm{~m} / \mathrm{min}$.

\section{Acknowledgment}

The presented research results, executed under the domestic project PBS of No 244445, were funded with grants for education allocated by the National Centre for Research and Development.

\section{References}

1. G. Kappmeyer, C. Hubiga, M. Hardy, M. Witty, M. Busch, Procedia CIRP 1

2. E.O. Ezugwu, J. Bonney, Y. Yamane, J. Mater. Process. Technol. 134 (2003)

3. S. Olovsjö, L. Nyborg, Wear 282- 283 (2012)

4. R. Polvorosa, A. Suárez, L.N. López de Lacalle, I. Cerrillo, A. Wretland, F. Veiga, Journal of Manufacturing Processes 26 (2017)

5. A.R. Motorcu, A. Kus, I. Durgun, Measurement 58 (2014)

6. A. Thakur, S. Gangopadhyay, International Journal of Machine Tools \& Manufacture 100 (2016)

7. A.R.C. Sharman, J.J. Hughes, K. Ridgway, Mach. Sci. Technol. 8(3) (2004)

8. S. Wojciechowski, P. Twardowski, M. Pelic, R.W. Maruda, S. Barrans, G. Krolczyk, Precision Engineering 46 (2016)

9. S. Wojciechowski, P. Twardowski, M. Pelic, Procedia CIRP 14 (2014)

10. S. Wojciechowski, R.W. Maruda, P. Nieslony, G.M. Krolczyk, International Journal of Mechanical Sciences 119 (2016)

11. D. Przestacki, T. Chwalczuk, S. Wojciechowski, Int J Adv Manuf Technol, DOI 10.1007/s00170017-0035-5 (2017)

12. D. Przestacki, P. Szymanski, S. Wojciechowski, Composites Part A: Applied Science and Manufacturing 911 (2016)

13. D. Przestacki, L. Marciniak-Podsadna, R. Majchrowski, Applied Surface Science, 388, part A, (2016)

14. R. W. Maruda, G. M. Krolczyk, M. Michalski, P. Nieslony, S. Wojciechowski, Journal of Materials Engineering and Performance 26 (2017)

15. R.W. Maruda, G.M. Krolczyk, P. Nieslony, S. Wojciechowski, M. Michalski, S. Legutko, Journal of Manufacturing Processes, 24, 1 (2016)

16. T. Kivak, Measurement $\mathbf{5 0}$ (2014)

17. S. Karabulut, Measurement 66 (2015)

18. G.M. Krolczyk, P. Niesłony, S. Legutko, Archives of Civil and Mechanical Engineering 15 (2) (2015)

19. X. Wang, I. S. Jawahir, International Journal of Production Research 43 (2005)

20. M. Subramanian, M. Sakthivel, K. Sooryaprakash, R. Sudhakaran, Measurement 46 (2013)

21. D. Przestacki, M. Jankowiak, Journal of Physics: Conference Series 483 (2014) 